\title{
Meso- and Microporous Carbon Electrode and Its Effect on the Capacitive, Energy and Power Properties of Supercapacitor
}

\author{
E. Taer ${ }^{1}$, R. Taslim ${ }^{2}$, Sugianto $^{3}$, M. Paiszal ${ }^{4}$, Mukhlis $^{5}$, W. S. Mustika ${ }^{6}$, Agustino $^{7}$ \\ 1,3,4,5,6,7 Department of Physics, University of Riau, Riau, Indonesia \\ ${ }^{2}$ Department of Industrial Engineering, Islamic State University of Sultan Syarif Kasim, Riau, Indonesia
}

\begin{tabular}{l} 
Article Info \\
Article history: \\
Received Jan 10, 2018 \\
Revised Aug 2, 2018 \\
Accepted Aug 6, 2018 \\
\hline Keyword: \\
Activated carbon monolith \\
EDLC \\
Meso- and microporous carbon \\
Specific capacitance
\end{tabular}

\section{Article history:}

Received Jan 10, 2018

Revised Aug 2, 2018

Accepted Aug 6, 2018

\section{Keyword: \\ EDLC \\ Specific capacitance}

\section{Corresponding Author:}

Erman Taer,

Departement of Physics,

University of Riau, Simpang Baru, Riau, Indonesia.

Email: erman_taer@yahoo.com

\begin{abstract}
Activated carbon monoliths (ACMs) for electrochemical double layer capacitor (EDLC) electrode with average pore diameters in the meso- and micropore regions were successfully produced from biomass material. ACM synthesis uses chemical activation with $\mathrm{KOH}$ and $\mathrm{ZnCl}_{2}$ activating agents. The carbon and activating agent mass ratios were 1:1, 1:3, 1:5 and 1:7. Both activating materials produced an ACM with an average pore diameter of 3.2 $\mathrm{nm}$. The specific capacitance, specific surface area, energy and power were as high as $63 \mathrm{~F} \mathrm{~g}^{-1}, 650 \mathrm{~m}^{2} \mathrm{~g}^{-1}$, and $0.23 \mathrm{Whkg}^{-1}$ for $\mathrm{KOH}$ and $73 \mathrm{~F} \mathrm{~g}^{-1}$, and $522 \mathrm{~m}^{2} \mathrm{~g}^{-1}$, and $19 \mathrm{~W} \mathrm{~kg}^{-1}$ for $\mathrm{ZnCl}_{2}$ activating agents, respectively. For comparison, we also studied the physical and electrochemical properties of $\mathrm{ACM}$ with an average pore size in the micropore range from the same raw material.
\end{abstract}

Copyright $(2018$ Institute of Advanced Engineering and Science. All rights reserved.

\section{INTRODUCTION}

An electrochemical double layer capacitor (EDLC), which is also known as a supercapacitor, is an energy storage device that is different from a battery, a fuel cell and a capacitor [1]. EDLC with exclusive features, almost unlimited number of charge-discharge cycles, very high capacitance and range of operational temperature, high power rating that is much more specific than most existing batteries so it can easily meet a very active charge [2] [3]. EDLC can be used in electric vehicle applications as energy storage devices while in combination with battery or fuel cells packs [2] [4] [5]. Currently, EDLC cells are widely researched and developed to fill the energy gap between the capacitor and battery. Energy storage in EDLC cells occurs due to the formation pairs of electrons and ions in the meso- and microporous regions of the carbon electrode that occurs at the boundary of the electrode and electrolyte [6]. Several ions and electron pairs are formed so more energy can be stored. The shape and size of the porous carbon electrode are key factors in determining the characteristics of the energy and power that is generated [7]. Variations in the pore size of porous carbon are usually grouped into several sizes: micropores, mesopores and macropores [8]. A micropore has an average pore diameter equal to or less than $2 \mathrm{~nm}$, mesoporouspore diameters range between $2 \mathrm{~nm}$ and $50 \mathrm{~nm}$, and the average pore diameter in a macropore is larger than $50 \mathrm{~nm}$ [9]. An electrode in which micropores are dominant will produce EDLC cells with higher energy characteristics; however, the generated power is relatively low [10]. A carbon electrode with an average pore size in the mesopore range will generate cell characteristics with relatively high power and low energy [11],[12]. One focus of research is to obtain an ideal average pore size to determine the optimum conditions for energy and power characteristics in an EDLC cell.

The pore characteristics of a carbon material are influenced by several factors, such as the raw materials and activation conditions [13]. One of the low-cost raw materials in the manufacturing of carbon is 
biomass material [14]. Several reports have stated that the pore characteristics of carbon derived from biomass materials have irregular shapes [15]. The pore characteristics of macrosized pores in the posterior section are reduced to micropore sizes in the deepest end [16]. A reduction in the macropore fraction can be achieved by adjusting the particle size of the carbon material. Activation methods that are commonly used in the manufacturing of porous carbon are physical and chemical activation methods [17]. Physical activation is carried out at relatively high temperatures of 800 to $900{ }^{\circ} \mathrm{C}$ with either $\mathrm{CO} 2$ or $\mathrm{H} 2 \mathrm{O}$ gas, and the activation time plays a role in determining the resulting pore size [18]. While the chemical activation is conducted with the help of chemical activating agents such as $\mathrm{KOH}, \mathrm{ZnCl} 2$, $\mathrm{HNO} 3$ or $\mathrm{H} 3 \mathrm{PO} 4$, the percentage mix between carbon materials and chemicals affects the pore size of the resulting carbon [19]. Another factor that plays a role in the formation of pores is the form of carbon produced. Carbon powders usually tend to have a pore size that is relatively uniform, whereas carbon pellets (monolithic) or granules have various pore sizes. [20]. Certain precursor materials in the production of carbon monolith electrodes usually produce a certain pore properties, a problem to be solved is to produce different pore properties from the same raw material.

In this research, the route to produce carbon pellets or monoliths from biomass material of rubber wood sawdust with different an average pore size in the meso- and microregions was demonstrated. Carbon monoliths were produced by grinding the raw material after a precarbonization process at low temperatures. The selection of an appropriate particle size and an assisted-molded operation generated the precarbonized powder that formed into a pellet shape without the assistance of an adhesive. The selected activation process was chemical activation using $\mathrm{KOH}$ and $\mathrm{ZnCl} 2$ on the precarbonized powder, whereas physical activation was performed by gaseous $\mathrm{CO} 2$ assistance that was conducted on the carbon pellet samples. The chosen production process route has successfully demonstrated monolith activated carbon with different pore properties, an average pore size in the meso- and microregions. The difference in pore properties of carbon monolith electrodes was analyzed by absorption and desorption methods using N2 gas, and EDLC cell characteristics were studied using cyclic voltammetry. This study has succeeded in showing the different electrode pore properties of the rubber wood sawdust material that causes variations in capacitance, energy and power in EDLC cells.

\section{RESEARCH METHOD}

Rubber wood that originated from a rubber plantation in Riau province, Indonesia, was used as the raw materials. A mechanical process was used to convert the rubber wood into sawdust. A fraction of the rubber wood sawdust in $\pm 2 \mathrm{~cm}$ was selected for this study. Chemical activation using $\mathrm{ZnCl} 2$ and $\mathrm{KOH}$ activating agents was selected for the meso and microporous studies on the activated carbon monolith from rubber wood sawdust.

The ACM was produced from rubber wood sawdust via a combination of chemical and physical activation methods. These methods started with a drying process of the rubber wood sawdust and precarbonization at temperatures of $250{ }^{\circ} \mathrm{C}$ for $2.5 \mathrm{~h}$. The ACM manufacturing process continued with grinding using a hard grinder and ball milling for $20 \mathrm{~h}$. Then, a sieving process was used to obtain powder with particle sizes less than $100 \mu \mathrm{m}$, and the powder was activated by a $\mathrm{ZnCl} 2$ solution. The samples were labeled ACM-Zs, whereas the samples that were activated by KOH were labeled ACM-Ks. The s index indicated the concentration of activated agent that was shown based on the ratio of the precarbonized sample mass and the activated material mass. The concentration ratios were 1:1, 1:3, 1:5 and 1:7. All samples ACM by different chemical activation agent were labeled as ACM-Z1, ACM-Z3, ACM-Z5, ACM-Z7, ACM-K1, ACM-K3, ACM-K5 and ACM-K7. A comparison of the electrode samples of microporous activated carbon monoliths was available through the method below. A particle size of less than $53 \mu \mathrm{m}$ was selected, and activation occurred using the same chemically activated agents $(\mathrm{KOH}$ and $\mathrm{ZnCl} 2)$ at a low concentration of 0.4 M. The samples were labeled ACM-Z0 and ACM-K0. All of the samples were carbonized in nitrogen gas from room temperature up to temperatures of $600{ }^{\circ} \mathrm{C}$ at a constant flow rate of $1.5 \mathrm{l} / \mathrm{min}$ by a previously reported technique [21], followed by $\mathrm{CO} 2$ gas at a temperature of $900{ }^{\circ} \mathrm{C}$ for $2 \mathrm{~h}$. All of the ACM electrodes were polished to thickness of $0.3 \mathrm{~mm}$ and washed using distilled water until the $\mathrm{pH}$ of the washing water was neutral.

Physical property measurements of the mass, diameter, thickness and porosity of the electrodes were conducted. Changes in the mass, thickness and diameter were shown and reported for each level of the preparation steps after both pellet manufacturing and physical activation. Porosity parameters were analyzed using the isothermal adsorption and desorption of nitrogen gas at a temperature of $77.3 \mathrm{~K}$ using a Quantachrome Instrument version 11.0. The specific surface area and pore volume STP was calculated by the Bruenauer-Emmett-Teller (BET) method of analysis.

Electrochemical properties measurements were conducted by using cyclic voltammetry methods. The CV testing was performed by a fabricated EDLC cell in coin form. Cyclic voltammetry was performed 
using a self-designed CV Physics UR Rad-Er 5841 instrument and calibrated with a Solartron 1280 potentiostat. The CV measurements were controlled using the software Cyclic Voltammetry CVv6. The measurements were conducted at a scan rate of $1 \mathrm{mV} \mathrm{s}-1$ with a potential window of $0-500 \mathrm{mV}$. The CV electrolyte used was $1 \mathrm{M} \mathrm{H} 2 \mathrm{SO} 4$. The performance measurements of the EDLC cells were calculated by the following formula [22].

$$
\mathrm{C}_{\mathrm{sp}}=\frac{2 \mathrm{I}}{\mathrm{s} \mathrm{m}}
$$

WhereI $=$ current, $\mathrm{s}=$ scan rate and $\mathrm{m}=$ electrode mass

\section{RESULTS AND ANALYSIS}

\subsection{Weight, Diameter and Thickness of the Electrode Analysis}

Figure 1 shows the changes in the weight, diameter and thickness of the monolithic carbon electrode both (i) after the activation process and (ii) as prepared. Figure 1a shows an electrode with a zinc chloride activation series, whereas Figure $1 \mathrm{~b}$ shows electrode samples with a potassium hydroxide activation series. The change in sample weight after the activation process shows the greatest reduction in diameter and thickness. The sample weight average is less than $60 \%$ of the original weight, and the diameter and thickness are reduced by 20 to $30 \%$. For example, the largest reduction in weight in the $\mathrm{Z}$ activation series occurs in the Z-5 sample, where the change in weight is consistent with the reduction in the diameter and thickness. The largest weight reduction in the K-series sample was observed with the ACM- K7 sample, and this change in weight is consistent with the change in diameter and thickness. It is believed that the change in weight is caused by dimensional changes in the electrode. The ACM-Z5 and ACM-K7 samples were predicted to demonstrate the best porosity properties. For each series, the weight change in the sample increases linearly with an increase in the activating concentration. In the $\mathrm{Z}$ series, optimum conditions were attained in the ACM-Z5 sample, whereas in the $\mathrm{K}$ series, the percentage increased with an increase in the activator. However, for samples with low activator concentrations materials ACM-Z0 and ACM-K0 exhibit higher mass changes. Smaller sample particle sizes are believed to cause more effective carbon and activator agent reactions that finally cause to greater mass reduction. The reduction in the diameter and thickness of the ACM-Z0 and ACM-K0 samples show the change is not so significant.
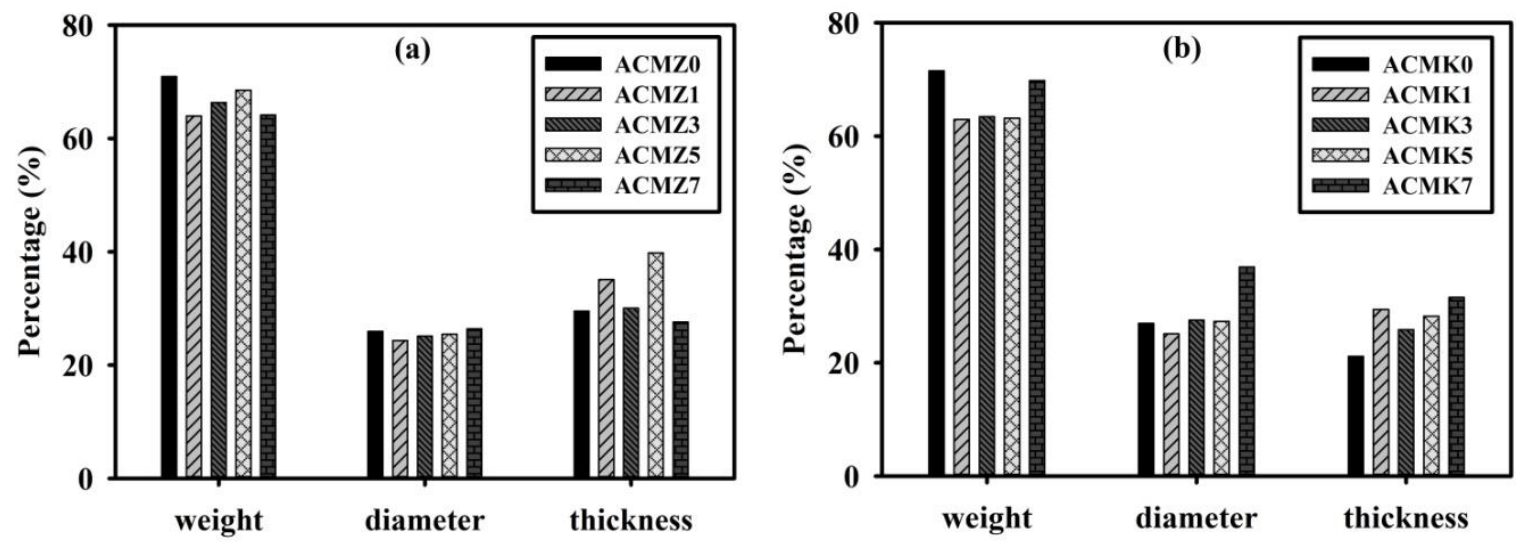

Figure 1.The change in weight, diameter, and thickness of the ACM electrode after activation process by (a) $\mathrm{ZnCl}_{2}$ and (b) $\mathrm{KOH}$ activating agent.

\section{2. $\mathrm{N}_{2}$ Gas Adsorption and Desorption}

Figure 2 shows the relation of the relative pressure to the amount of $\mathrm{N} 2$ gas absorbed in the sample pores. The data for the samples with an activation series of $\mathrm{ZnCl} 2$ and $\mathrm{KOH}$ are shown in Figures $2 \mathrm{a}$ and $\mathrm{b}$ and Figures $2 c$ and d, respectively. These figures show the relationship between the pore size and the volume of absorbed N2 gas. In Figure 2a, the samples in the $\mathrm{ZnCl} 2$ series show type IV, which is based on the IUPAC classification [8]. The adsorption-desorption data show the hysteresis patterns that appear in the relative pressure area between 0.4 and 1. This type IV data has a characteristic average pore size in the mesoporous range. The $\mathrm{Z}$ sample series shows that if more activating materials are used in the activation 
process, then more $\mathrm{N} 2$ gas is absorbed. A similar pattern of curves was also encountered in the $\mathrm{KOH}$ series of samples. For samples in the $\mathrm{K}$ series, it was found that adding $\mathrm{KOH}$ concentrations clearly influenced the increase in $\mathrm{N} 2$ gas absorption in the volume. However, this trend was clearly not observed in the $\mathrm{Z}$ activation series sample. The inserts in Figure $2 \mathrm{a}$ and $2 \mathrm{~b}$ show a type I pore model for the ACM-K0 and ACM-Z0 samples, which indicate the average pore of the sample in the micropore size range. Figure $2 \mathrm{c}$ shows that the pattern of the pore diameter variation in sample size appears in the range of 30 to $140 \AA$. All quantities of activating materials indicate that the $\mathrm{N} 2$ gas absorption volume is almost the same for all samples in a pore diameter range of 100 to $140 \AA$, except the volume is slightly higher for the ACM-Z5 sample. In the lower pore diameter range in the region from 50 to $100 \AA$, sample ACM-Z5 has the highest amount of absorbed gas and exhibits a low peak at a pore diameter size of $54 \AA$, whereas the other samples exhibit similar pore distribution patterns. Furthermore, in a small pore diameter range of $50 \AA$, sample ACM-Z5 has the highest absorption volume, followed by samples ACM-Z1, ACM-Z3 and ACM-Z7. For all samples, the highest absorption occurs at nearly the same pore diameter that is in the region of $36 \AA$. Larger absorption volumes indicate the presence of higher pore amounts with almost the same pore diameter. This fact indicates that an increased activator concentration causes an increase in the number of pores formed on the carbon electrode. Figure $2 \mathrm{~d}$ shows the pore size distribution pattern for the $\mathrm{K}$ series samples, which indicates that the absorption volume pattern looks almost the same in the pore diameter range of 140 to $40 \AA$. Different absorption patterns for the $\mathrm{K}$ series electrodes are exhibited in the small pore diameter areas of $40 \AA$. The ACM-K7 sample showed the highest absorption volume, and the ACM-K1 sample showed the smallest absorption volume. These results indicate that the pore distribution for the $\mathrm{K}$ series samples has the same pattern but differs only in the amount of mesopores that are formed, especially in a pore diameter of approximately $30 \AA$. Based on Figures $2 \mathrm{c}$ and d, the different activating materials ( $\mathrm{ZnCl} 2$ and $\mathrm{KOH})$ show the pore distribution pattern of the monolithic carbon electrode; however, both types of electrode series of the monolith are still equally in the mesopore range.
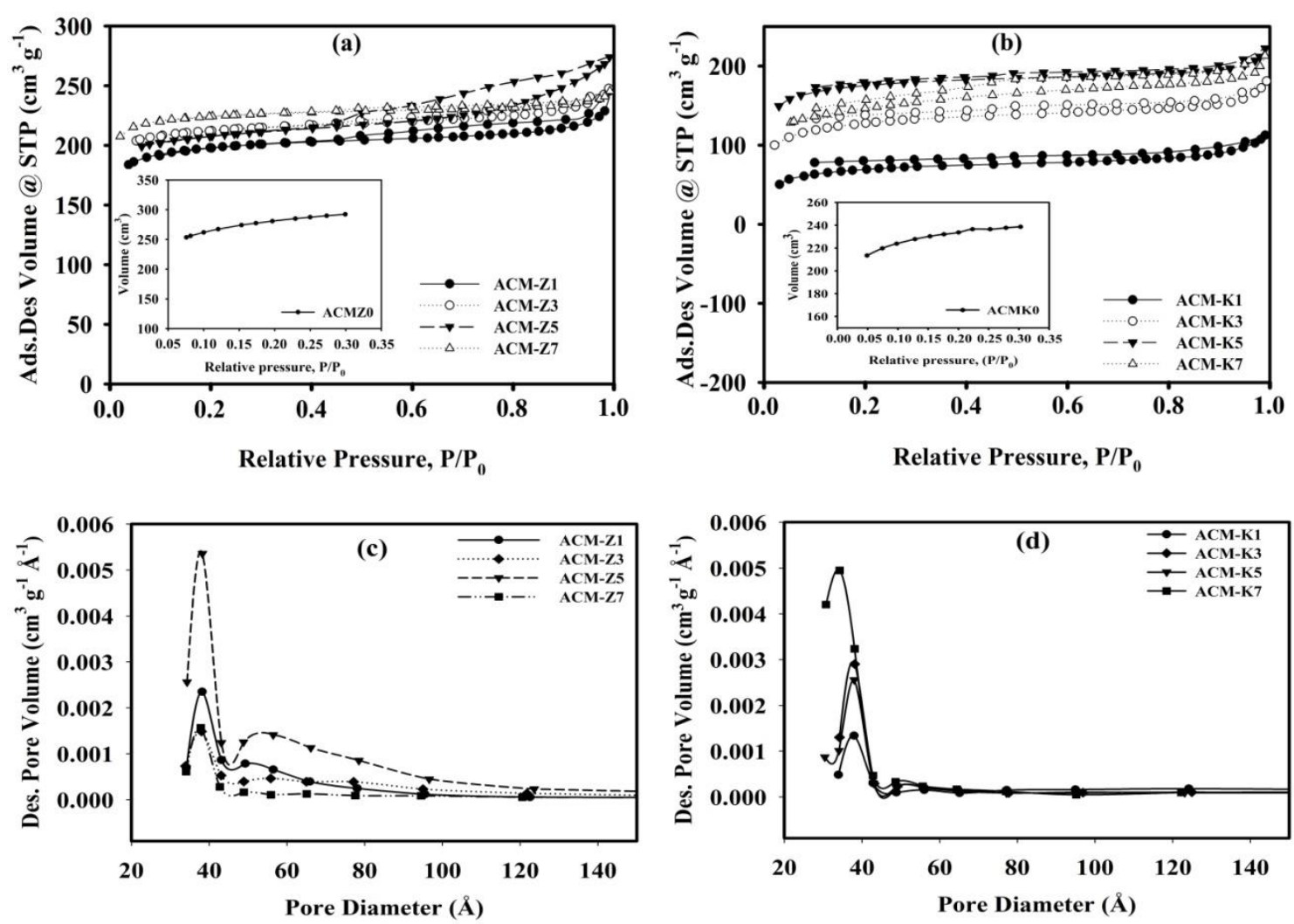

Figure 2.The $\mathrm{N}_{2}$ adsorbtion-desorption data for (a) ACM-Z sampels and (b) ACM-K samples, $\mathrm{N}_{2}$ volume adsorption data vs pore diameter in (c) ACM-Z sampels and (d) ACM-K samples 
Table 1 shows the pore properties of monolithic carbon electrodes for samples with an activated series of zinc chloride and potassium hydroxide. The pore properties that are shown for each sample are the BET surface area $\left(\mathrm{S}_{\mathrm{BET}}\right)$, mesoporous surface area $\left(\mathrm{S}_{\text {meso }}\right)$, micropore surface area $\left(\mathrm{S}_{\text {micro }}\right)$, total pore volume $\left(\mathrm{V}_{\text {total }}\right)$, micropore volume $\left(\mathrm{V}_{\text {micro }}\right)$ and average pore diameter $(\mathrm{D})$. For the $\mathrm{Z}$ series electrodes, sample ACM$\mathrm{Z7}$ has the highest surface area, and the value of the surface area of the $\mathrm{Z}$ series sample is not significantly different for increasing concentrations of the activator. For the $\mathrm{K}$ series electrode samples, an increase in activator concentration significantly affects the sample surface area, and the ACM-K5 sample shows the optimum surface area. The mesoporous opening area looks different for the $\mathrm{Z}$ activation series samples with ACM-Z5 showing the highest mesoporous surface area. For the $\mathrm{K}$ activation series, the highest surface area of mesopores is shown in the ACM-K7 sample, but the other samples ACM-K1, ACM-K3 and ACM-K5 show almost the same mesoporous surface area. The pore test results on the ACM electrodes show a correlation between the mesoporous surface area with changes in weight and dimension in each sample series. Samples with the highest mesoporous surface area display the highest weight and dimensional changes.

Table 1.The porosity characteristic for ACM samples

\begin{tabular}{lcccccc}
\hline Cells & $\begin{array}{c}\mathrm{S}_{\text {BET }} \\
\left(\mathrm{m}^{2} \cdot \mathrm{g}^{-1}\right)\end{array}$ & $\begin{array}{c}\mathrm{S}_{\text {MESO }} \\
\left(\mathrm{m}^{2} \cdot \mathrm{g}^{-1}\right)\end{array}$ & $\begin{array}{c}\mathrm{S}_{\text {MICRO }} \\
\left(\mathrm{m}^{2} \cdot \mathrm{g}^{-1}\right)\end{array}$ & $\begin{array}{c}\mathrm{V}_{\text {TOTAL }} \\
\left(\mathrm{cm}^{3} \cdot \mathrm{g}^{-1}\right)\end{array}$ & $\begin{array}{c}\mathrm{V}_{\text {MICRO }} \\
\left(\mathrm{cm}^{3} \cdot \mathrm{g}^{-1}\right)\end{array}$ & $\begin{array}{c}\mathrm{D} \\
(\mathrm{nm})\end{array}$ \\
\hline ACM-Z1 & 580 & 34.367 & 564 & 0.380 & 0.306 & 3.818 \\
ACM-Z3 & 613 & 28.681 & 595 & 0.383 & 0.326 \\
ACM-Z5 & 609 & 80.105 & 572 & 0.424 & 0.312 & 3.801 \\
ACM-Z7 & 650 & 16.243 & 638 & 0.380 & 0.346 & 3.825 \\
ACM -K1 & 215 & 19.654 & 183 & 0.174 & 0.104 \\
ACM -K3 & 391 & 29.078 & 362 & 0.280 & 0.198 \\
ACM -K5 & 522 & 29.782 & 496 & 0.344 & 0.273 & 3.796 \\
ACM -K7 & 454 & 66.22 & 425 & 0.330 & 0.229 \\
\hline
\end{tabular}

\subsection{Capacitive Properties}

The capacitive properties of EDLC cells for the monolithic carbon electrodes of the $\mathrm{Z}$ and $\mathrm{K}$ series are represented by Figures $3 \mathrm{a}$ and $\mathrm{b}$, respectively. The cyclic voltammogram was measured at a potential window of 0 to $0.5 \mathrm{~V}$ at a scan rate of $1 \mathrm{mV} \mathrm{s}^{-1}$. The $\mathrm{CV}$ results using the $\mathrm{C}_{\mathrm{sp}}=\mathrm{I} /(\mathrm{m} . \mathrm{s})$ formula are shown as the relationship of potential vs. specific capacitance [22]. The CV curves that are shown for the two-electrode series are ideal curves for carbon-based electrodes. The curve clearly resembles a rectangular shape [23]. At a low potential of close to $0.02-0.05 \mathrm{~V}$, there is a significant increase in the specific capacitance for both series of samples. Increasing the capacitance at low voltage results in a large increase in current. This electrode property usually indicates a smooth ion diffusion process into the pores of the carbon electrode during the process [24]. This result is only possible if the average pore diameter of the electrode is large enough for the ions to enter [25]. At higher potentials in the range of $0.05 \mathrm{~V}-0.5 \mathrm{~V}$, an increase in the specific capacitance of the EDLC cells slowly occurs with increasing potential. This process indicates that the potential increase no longer significantly influences the increase in the ion amount in the electrode pores to form charged pairs. Furthermore, a potential of $0.5 \mathrm{~V}-0.4 \mathrm{~V}$ indicates the beginning of the discharge process where there is a significant decrease in the capacitance value, which slowly decreases toward a zero potential. The nature of the charge-discharge process is shown by the entire series of cells. This EDLC shows ideal characteristics of a supercapacitor cell. Such features usually occur in carbon electrodes with an average pore size in the mesoporous range. These results are consistent with the test results of the electrode pore properties, in which all the tested electrodes have average pore diameters in the 3-nm range. For confirmation, we have also measured the capacitive properties of EDLC cells using electrodes that were activated with $\mathrm{Z}$ and $\mathrm{K}$ at low concentrations. The data in Figures $3 \mathrm{a}$ and $\mathrm{b}$ show clear differences in the shape of the curve, where it appears that the specific capacitance of the electrode slowly increases starting from a potential of 0 to $0.5 \mathrm{~V}$. This characteristic suggests that the process of ion diffusion into the electrode pores proceeds in the presence of obstacles [26]. The same results were also shown for carbon electrode samples with an average pore size in the micropore range [27]. Figures $3 \mathrm{a}$ and $\mathrm{b}$ show that the proportion of samples with low $\mathrm{Z}$ and $\mathrm{K}$ concentration produce electrodes with pore averages in the micropore range.

Table 2 presents the capacitive properties of EDLC cells such as specific capacitance, specific energy and specific power. The specific capacitance of the EDLC cell for a Z or K series mesoporous carbon electrode is in range from 38 to $73 \mathrm{~F} \mathrm{~g}^{-1}$. For the EDLC cell in the $\mathrm{Z}$ series, the optimum specific capacitance was found in the ACM-Z3 sample, which is equal to $63 \mathrm{~F} \mathrm{~g} \mathrm{~g}^{-1}$, whereas for the EDLC in the $\mathrm{K}$ series, the highest capacitance obtained in the EDLC cell with the ACM-K5 electrode is $73 \mathrm{~F} \mathrm{~g} \mathrm{~g}^{-1}$. The specific capacitance is correlated with the surface area of $\mathrm{S}_{\mathrm{BET}}$ and the micropore surface area. The EDLC cells with 
electrodes at a high percentage of micropore surface area tend to produce high specific capacitances. When the EDLC cells with ACM-Z3 and ACM-K5 electrodes are compared with the EDLC cells ACM-Z0 and ACM-K0, the specific capacitance of ACM-Z3 and ACM-K5 are relatively comparable. The electrodes ACM-Z0 and ACM-K0 have relative higher $\mathrm{S}_{\mathrm{BET}}$ surface areas. The surface areas of ACM-Z0 and ACM-K0 samples are related to the high value of the specific capacitance. On the other hand, EDLC cells with the highest specific capacitance, i.e., ACM-Z3 and ACM-K5, produce the optimum energy and power densities.
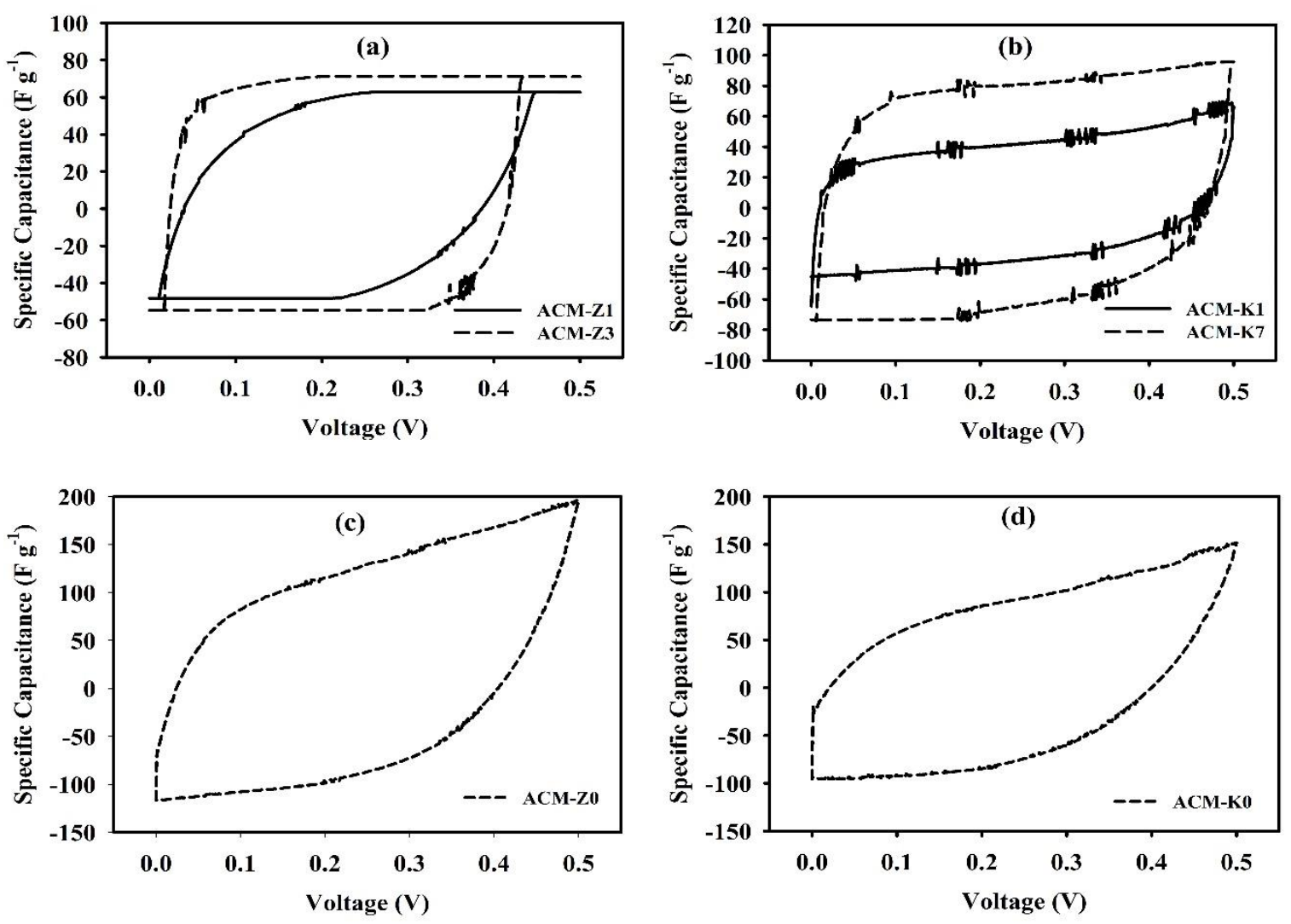

Figure 3.The CV curve for diferent cell with electrode of (a) ACM-Z, (b) ACM-K, (c) ACM-Z0 and (d) ACM-K0

Table 2.The BET surface area $\left(\mathrm{S}_{\mathrm{BET}}\right)$, Specific capacitance $\left(\mathrm{C}_{\mathrm{sp}}\right)$, Energy density $(\mathrm{W})$ and Power density $(\mathrm{P})$ for supercacitor cells

\begin{tabular}{ccccc}
\hline Cells & $\begin{array}{c}\mathrm{S}_{\mathrm{BET}} \\
\left(\mathrm{m}^{2} \cdot \mathrm{g}^{-1}\right)\end{array}$ & $\begin{array}{c}\mathrm{Csp} \\
\left(\mathrm{F} \mathrm{g}^{-1}\right)\end{array}$ & $\begin{array}{c}\mathrm{W} \\
\left(\mathrm{Whkg}^{-1}\right)\end{array}$ & $\begin{array}{c}\mathrm{P} \\
\left(\mathrm{W} \mathrm{kg} \mathrm{kg}^{-1}\right)\end{array}$ \\
\hline ACM-Z0 & 883 & 100 & 0.21 & 18.71 \\
ACM-Z1 & 580 & 54 & 0.15 & 14.52 \\
ACM-Z3 & 613 & 63 & 0.17 & 16.47 \\
ACM-Z5 & 609 & 60 & 0.17 & 15.64 \\
ACM-Z7 & 650 & 55 & 0.15 & 14.34 \\
ACM-K0 & 719 & 60 & 0.18 & 16.80 \\
ACM-K1 & 215 & 38 & 0.02 & 8.05 \\
ACM-K3 & 391 & 44 & 0.03 & 9.89 \\
ACM-K5 & 522 & 73 & 0.23 & 19.64 \\
ACM-K7 & 454 & 72 & 0.03 & 18.74 \\
\hline
\end{tabular}

\subsection{X-Ray analysis}

A comparison of crystallinity properties of the activated carbon monoliths in meso- and micropores is shown in Figure 4. Each sample of ACM-K5 and ACM-K0 is selected to represent mesoporous and microporous characteristics. These results show the relationship between the intensity of the X-ray diffraction peaks and $2 \theta$ scattering angle. The crystals that exhibit the highest intensity appear at a $2 \theta$ angle of $30^{\circ}$. This 
finding indicates the presence of $\mathrm{SiO}_{2}$, which is commonly present for carbon materials derived from biomass [16]. Additionally, the presence of sharp peaks at a $2 \theta$ of $23^{\circ}, 36^{\circ}, 39^{\circ}, 43^{\circ}, 47^{\circ}, 48^{\circ}$ and $57^{\circ}$ represents $\mathrm{KCl}$ materials that was derived from chemical activation processes and not released during the washing and burning process [28]. Both curves show two broadening peaks, which indicate an amorphous characteristic of the carbon material, at an angle of $2 \theta$ equal to $26.329^{\circ}$ and $45.659^{\circ}$ for $\mathrm{ACM}-\mathrm{K} 5$ and $25.344^{\circ}$ and $46.768^{\circ}$ for ACM-K0 [29]. The differences in pore structure resulted in different $d_{002}$ interlayer spacings for ACM-K5 and ACM-K0. On the other hand, the $\mathrm{d}_{100}$ interlayer showed no significant difference for ACM-K5 and ACM-K0. Therefore, the $\mathrm{L}_{c}$ and $\mathrm{L}_{\mathrm{a}}$ of each sample are different. The $\mathrm{L}_{\mathrm{c}}$ and $\mathrm{L}_{\mathrm{a}}$ are $1.212 \mathrm{~nm}$ and $0.637 \mathrm{~nm}$ for ACM-K5 and $1.233 \mathrm{~nm}$ and $0.636 \mathrm{~nm}$ for ACM-K0. These data suggest that the formation of pore structure is determined by the particle size and concentration of the activating agent. ACM-K5 with a high concentration of activator indicates the arrangement tendency of the atomic lattice plane toward vertical so that high $\mathrm{L}_{\mathrm{c}}$ is obtained. Moreover, ACM-K0 with a micropore structure that was obtained through the formation of a small particle size is caused by a growth in the arrangement of the lattice plane of the atom in the horizontal direction. The interlayer spacing data correlates with the porosity data. High $\mathrm{L}_{\mathrm{c}}$ in the direction of the lattice arrangement on the horizontal plane results in a larger mesopore size for ACM-K5. On the other hand, the high $\mathrm{L}_{\mathrm{a}}$ value in the direction of the horizontal arrangement of the lattice planes is obtained by the high BET surface area for ACM-K0. The ratios of $\mathrm{L}_{c} / \mathrm{L}_{\mathrm{a}}$ are 1.901 for ACM-K5 and 0.515 for ACM-K0. The $\mathrm{L}_{\mathrm{c}} / \mathrm{L}_{\mathrm{a}}$ ratios support the above statement that the mesoporous structure of ACM-K5 is generated by modifying the growth of the lattice plane arrangement of the atoms toward the vertical, whereas the modification of the high BET surface area on ACM-K0 results from the horizontal arrangement of the lattice planes. These data show $\mathrm{L}_{\mathrm{c}} / \mathrm{d}$ lattice ratio values of 3.584 for ACM-K5 and 1.811 for ACM-K0, which indicate that the vertical lattice grid growth corresponds to an increasing number of lattice piles.

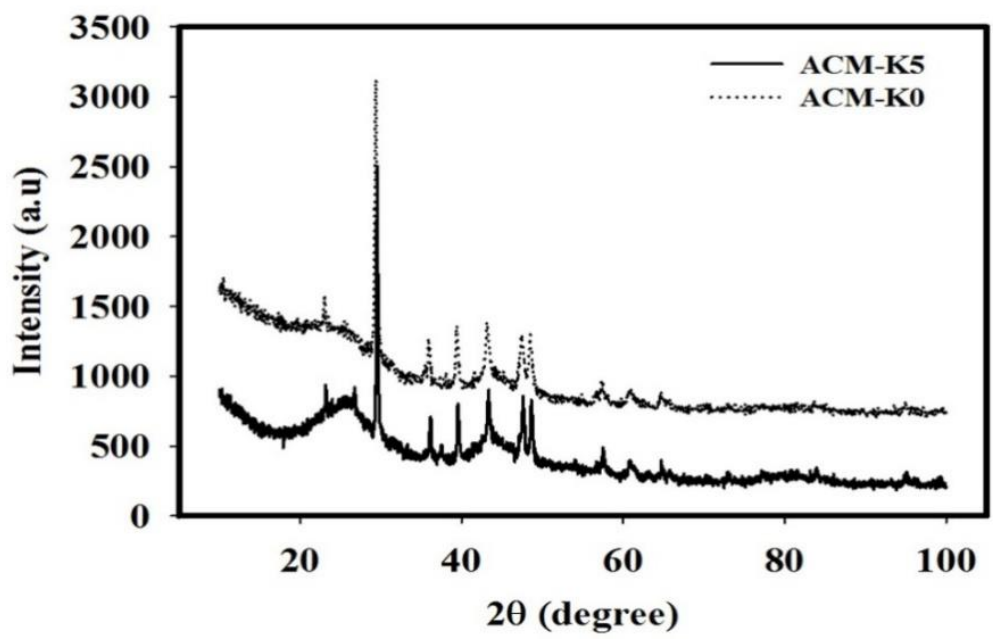

Figure 4. The X-ray difraction curve for ACM-K5 and ACM-K0

Table 3. The XRD data for ACM-K0 and ACM-K5

\begin{tabular}{ccccccccc}
\hline $\begin{array}{c}\text { Samples } \\
\text { Code }\end{array}$ & $\begin{array}{c}2 \theta \\
(002)\end{array}$ & $\begin{array}{c}2 \theta \\
(100)\end{array}$ & $\begin{array}{c}\mathrm{d}_{002} \\
(\AA)\end{array}$ & $\begin{array}{c}\mathrm{d}_{100} \\
(\AA)\end{array}$ & $\begin{array}{c}\mathrm{Lc} \\
(002)\end{array}$ & $\begin{array}{c}\mathrm{La} \\
(100)\end{array}$ & $\mathrm{Lc} / \mathrm{La}$ & $\mathrm{Lc} / \mathrm{d}_{002}$ \\
\hline ACM-K0 & 25.344 & 46.768 & 3.51143 & 1.94083 & 6.35759 & 12.3337 & 0.51547 \\
ACM-K5 & 26.329 & 45.659 & 3.382253 & 1.98536 & 12.1204 & 6.37392 & 1.90156 & 3.58352 \\
\hline
\end{tabular}

Overall, the analyses demonstrate that rubber wood sawdust biomass material can be selected as the origin material in the production of meso- and microporous-activated carbon electrodes in monolith form for EDLC applications. The $\mathrm{Z}$ and $\mathrm{K}$ activators are effective enough to produce mesoporous-activated carbon electrodes in monolithic forms. The difference ratio of the $\mathrm{Z}$ activator on the mixture of $1,3,5$ and 7 is not significantly influenced by changes in the physical and capacitive characteristics of the electrode. This result is clearly visible from the weight change, surface area and capacitive property data. This fact may be due to the $\mathrm{Z}$ activator more effectively reacting with the precarbonized material from the rubber wood sawdust, which is indicated by the relatively high value of the surface of the ACM-ZO electrode, where it is activated 
at low $\mathrm{Z}$ concentrations. The ACM-Z0 electrode produces an average pore size in the micropore range. An increase in the percentage of activating materials to carbon and $\mathrm{ZnCl}_{2}$ ratios of 1 and 3, respectively, is sufficient to extend the ACM-Z0 micropores into the mesopore range on samples $\mathrm{Z} 1$ and $\mathrm{Z} 3$ with an average pore size of $3.8 \mathrm{~nm}$. In contrast, in the $\mathrm{K}$ series, the optimum carbon mesopores as carbon monoliths for EDLC electrodes are more effectively produced on relatively high percentages of precarbonized powder and $\mathrm{KOH}$ with ratios of 1: 5 and 1: 7, respectively.

\section{CONCLUSION}

Biomass-based meso- and micropores carbon electrodes from rubber wood sawdust using chemical activation for EDLC applications have shown good capacitive properties. $\mathrm{ZnCl}_{2}$ and $\mathrm{KOH}$ at carbon and activator agent ratios of 1:3 and 1:5, respectively, have been demonstrated with activated carbon in mesoporous size with optimum capacitive properties. The maximum specific capacitance for each activator is 63 and $73 \mathrm{~F} \mathrm{~g} \mathrm{~g}^{-1}$ for ACM-Z3 and ACM-K5 samples, respectively. Increasing the ratio of the precarbonized material and $\mathrm{ZnCl}_{2}$ to $1: 3$ facilitated a change in the average pore size from the micropore range to the mesopore range. However, for the $\mathrm{KOH}$ activator, changes in micro- to mesopore regions were observed at a higher ratio of 1:5 for the precarbonized material and activator agent. Finally, it can be concluded that rubber wood sawdust is a potential raw material for the production of carbon electrode EDLC in both the meso- and micropore regions.

\section{ACKNOWLEDGEMENTS}

We acknowledge DRPM KEMENRISTEK-DIKTI for the research funding under grant HIBAH PDUPT no. 539/UN/19.5.1.3/PP/2017.

\section{REFERENCES}

1. R. Kotz and M. Carlen,"Principles and applications of electrochemical capacitors,"ElectrochimicaActa,vol. 45, pp. 2483-2498, 2000

2. A.K.M.A. Habib, et al.," A series regeneration converter technique for voltage balancing of energy storage devices," Indonesian Journal of Electrical Engineering and Computer Science, vol. 8, pp. 475-481, 2017.

3. U. Sirmelis and L. Grigans,"Capacitance balancing for supercapacitive energy storage system," Proc. Int. Symp. Electr. Power Eng. Pärnu. 2011, pp. 38-41.

4. S. Dhameja,"Electric vehicle battery systems," USA, Newnes, 2001.

5. C. Zhao, et al,'Two-level energy management strategy for a fuel cell-battery-ultracapacitor hybrid system,"Industrial Electronics Society, IECON 2016-42nd Annual Conference of the IEEE. Florence. 2016, pp. 2135-2140.

6. P. Sharma and T.S. Bhatti,"A review on electrochemical double-layer capacitors," Energy Conversion and Management, vol. 51,pp. 2901-2912, 2010.

7. A. González, et al.,"Review on supercapacitors: technologies and materials,"Renewable and Sustainable Energy Reviews, vol. 58,pp. 1189-1206, 2016.

8. K.S.W. Sing, et al.,"Reporting physisorption data for gas/solid systems with special reference to the determination of surface area and porosity,"Pure and Applied Chemistry, vol. 57, pp.603-619, 1985.

9. A. Aworn, et al.,"Preparation and characteristics of agricultural waste activated carbon by physical activation having micro- and mesopores,"Journal of Analytical and Applied Pyrolysis, vol. 82,pp. 279-285, 2008.

10. M.P. Bichat, et al.,"High voltage supercapacitor built with seaweed carbons in neutral aqueous electrolyte," Carbon, vol. 48,pp. 4351-4361, 2010.

11. K.-W Chang,et al.,,"'Synthesis of mesoporous carbon by using polymer blend as template for the high power supercapacitor,"Diamon\& Related Mater,vol. 18, pp. 448-451, 2009.

12. X. He, et al., "Efficient preparation of biomass-based mesoporous carbons for supercapacitors with both high energy density and high power density,"Journal Power Sources, vol. 240, pp. 109-113, 2013.

13. M. Inagaki, et al.,"Carbon materials for electrochemical capacitors," Journal Power Sources, vol. 195,pp. 78807903, 2010.

14. A. M. Abioye and F. N. Ani,"Recent development in the production of activated carbon electrodesfrom agricultural waste biomass for supercapacitors: A review," Renewable and Sustainable Energy Reviews, vol. 52, pp.1282-1293, 2015.

15. R. Farma, et al.,"Preparation of highly porous binderless activated carbon electrodes from fibres of oil palm empty fruit bunches for application in supercapacitors,"BioresourceTechnology, vol. 132, pp. 254-261, 2013.

16. E. Taer, et al.,"'Preparation of a Highly Porous Binderless Activated Carbon Monolith from Rubber Wood Sawdust by a Multi-Step Activation Process for Application in Supercapacitors,"International Journal ofElectrochemical Science, vol. 6,pp. 3301-3315, 2011. 
17. E. Taer, et al.,"Preparation of Activated Carbon Monolith Electrodes from Sugarcane Bagasse by Physical and Physical-chemical Activation Process for Supercapacitor Application,"Advanced Materials Research, vol. 896, pp. 179-182, 2014.

18. E. Taer, et al.," Physical, electrochemical and supercapacitive properties of activated carbon pellets from precarbonized rubber wood sawdust by $\mathrm{CO}_{2}$ activation,"CurrentAppliedPhysics,vol. 10, pp.1071-1075, 2010.

19. Y-T. Li, et al.,"'Hierarchical porous active carbon from fallen leaves by synergy of $\mathrm{K}_{2} \mathrm{CO}_{3}$ and their supercapacitor performance," Journal Power Sources, vol. 299, pp. 519-528, 2015.

20. A. Garcia-Gomez, et al.,"Why Carbon Monoliths are Better Supercapacitor Electrodes than Compacted Pellets,"Electrochemical Solid State Letters, vol. 13 (8), pp. A112-A114, 2010.

21. E. Taer, et al.,"Preparation of Binderless Activated Carbon Monolith from Pre-Carbonization Rubber Wood Sawdust by Controlling of Carbonization and Activation Condition," AIP ConferenceProceeding,2013, pp.33-37.

22. E. Taer, et al.,"'Preparation and Characterizations of Activated Carbon Monolith From Rubber Wood and Its Effect on Supercapacitor Performances," AIP ConferenceProceeding,2016, pp. 050011-1-050011-5.

23. E. Taer, et al.,"Growthofplatinumnanoparticlesonstainlesssteel316Lcurrentcollectorsto improve carbonbased supercapacitorperformance." ElectrochimicaActa,vol. 56,pp. 10217-10222, 2011

24. P. Simonand Y. Gogotsi,"'Charge storage mechanism in nanoporous carbons and its consequence for electrical double layer capacitors," Philosophical Transactions of the Royal Society A, vol. 368, pp.3457-3467, 2010.

25. P. Simon and Y. Gogotsi,"Materials for electrochemical capacitors," Nature Materials, Vol. 7,pp. 845-854, 2008.

26. C.-W. Huang, et al.,"Mesoporous carbon spheres grafted with carbon nanofibers for high-rate electric double layer capacitors,"Carbon, vol. 49,pp. 895-903, 2011.

27. A.G.Pandolfo and A. F. Hollenkamp,"Carbon properties and their role in supercapacitors,"Journal Power Sources, vol. 157,pp. 11-27, 2006.

28. T. E. Rufford, et al.,"Microstructure and electrochemical double-layer capacitance of carbon electrodes prepared by zinc chloride activation of sugar cane bagasse,"Journal Power Sources, vol. 195,pp. 912-918, 2010.

29. E. Taer, et al.,"Activated carbon electrode from banana-peel waste for supercapacitor applications," AIP ConferenceProceeding,2017,pp. 040004-1-040004-4. 